\title{
Construyendo el pasado territorial indígena. Comunalización y sentidos de pertenencia comechingón del Pueblo de La Toma (Ciudad de Córdoba)
}

\section{Building the indigenous territorial past. Communalization and sense of belonging comechingón of the Pueblo de La Toma (Córdoba City)}

Lucas Palladino ${ }^{1}$

\begin{abstract}
RESUMEN
En el año 2007 comenzaron a visibilizarse en Córdoba comunidades comechingonas. Se trata de pueblos indígenas considerados extintos por los relatos hegemónicos sobre el pasado cordobés. En este contexto se rearticula la Comunidad Comechingona del Pueblo de La Toma ubicada en la ciudad de Córdoba. Esta reemergencia se ha trazado en medio de disputas en las cuales ciertos sectores continúan argumentando que los comechingones se extinguieron. En este marco, los comuneros han tendido a fortalecer la historia propia en la que consideran que han continuado viviendo en el territorio. Así, aquí partimos de la tensión entre los imaginarios hegemónicos sobre la identidad nacional y aquellos que los comechingones disputan. Particularmente, a través de nuestra investigación etnográfica realizada entre los años 2008 y 2017, analizamos el papel que han tenido las prácticas de construcción del pasado territorial comechingón y el lugar otorgado a las fuentes documentales y catastrales en dicho proceso.
\end{abstract}

Palabras clave: Comechingones, comunalización, pasado territorial, imaginarios, nación.

\section{ABSTRACT}

In 2007, comechingon communities began to visible in Córdoba. These are natives peoples considered extinct by hegemonic stories about the Cordoba's past. In this context, it is re-articulated La Toma's Comechingon Community, located in Córdoba's city. This re-emergence has been trace amid disputes in which certain sectors continue to argue that the comechingones became extinct. In this environment, the community members have tended to strengthen their own history in which they consider they have continued to live in the territory. Thereby, in this article we start from the tension between the hegemonic imaginary about national identity and those who comechingon peoples dispute. Particularly, through our ethnographic research carried out between 2008 and 2017, we analyze the role of the construction practices of the comechingón territorial past and the place granted to the documentary and cadastral sources in said process.

Key words: Comechingones, communalization, territorial past, imaginary, nation. 
Desde la perspectiva de algunos investigadores y aficionados de los campos de la etnohistoria y la arqueología, los comechingones junto con sanavirones y ranqueles fueron las etnias indígenas que habitaron la provincia de Córdoba (Argentina). A lo largo del siglo XX se los consideró como una "cultura extinta" debido al paso de la colonización hispánica, el trabajo forzoso al que se sometieron producto de la incorporación como mano de obra a las encomiendas, y luego por la desaparición de las "comunidades" o pueblos de indios en el periodo que abarca desde la independencia hasta la consolidación del Estado-Nación argentino (1810-1880). Así, el conocimiento público sobre los pueblos indígenas de esta provincia quedó sujeto a una literatura académica que sostenía dicha extinción reforzando los imaginarios que preterizaron (Bompadre, 2016) a dichos pueblos, ubicando la posibilidad de su existencia sólo en el pasado y los espacios rurales de la misma provincia.

Sin embargo, a finales del siglo $\mathrm{XX}$ y a comienzos del corriente se manifestaron procesos públicos de adscripción de comechingones y también formación de comunidades indígenas en diferentes zonas (predominantemente rurales) del territorio provincial ${ }^{2}$. Una de las primeras en reorganizarse fue la Comunidad Comechingón del Pueblo de La Toma, a finales del 2007 y comienzo del 2008, cuando se visibilizaron públicamente como originarios. Esta comunidad ha tenido la particularidad de ser la única que se reivindica en un espacio urbano, identificándose como indígenas preexistentes a la fundación de la ciudad de Córdoba (1573). Se trata de un de un pueblo de indios que es efecto de la reducción de algunas comarcas indígenas preexistentes a la ciudad, que es localizado en su margen oeste, donde se construyó una acequia y una toma (que le diera el nombre al pueblito allí ubicado) para abastecer de agua a la Córdoba colonial (siglos XVI a XIX). El Pueblo de La Toma, que, ya reconocida como comunidad indígena, fue sometido a un proceso de expropiación de tierras durante las últimas décadas del siglo XIX hasta 1910 cuando pasa a denominarse barrio Alberdi ${ }^{3}$.

Debido a estos procesos, los comuneros que se reivindicaron como comechingones consideraron que rearticularían su comunidad que había estado oculta y en silencio después de casi un siglo. Por un lado, se restableció el sistema de organización política por curacazgo, es decir de siete curacas que representaban a las familias reconocidas, por el otro, se realizaron una serie de prácticas hacia el exterior, que estuvieron mayormente ligadas al reconocimiento social y político de su identidad identidad indígena. En este plano la comunidad logró el reconocimiento de la pre-existencia étnica y territorial frente al Estado Nación, obteniendo la personería jurídica del Instituto Nacional de Asuntos Indígenas (INAI) en 2010.

\footnotetext{
Diversos estudios muestran estos procesos de reconocimiento, constitución política y/o reemergencias de grupos considerados extintos en Argentina a partir de 1990 (Briones, 1998, 2005, Gordillo y Hirsch, 2010, Escolar, 2007, Lazzari, 2010). Los procesos mencionados ocurrieron primeramente en el norte (en las zonas limítrofes con Bolivia y Paraguay, provincias de Salta, Jujuy, Chaco y Formosa) y en el sur del país (en la región patagónica: principalmente en Neuquén, Río Negro, Chubut y Santa Cruz, en el límite con Chile). Sin embargo, y tal como lo muestran los trabajos de Escolar (2007) y Lazzari, (2010) también se observan reemergencias indígenas en el centro y centro oeste, con comunidades huarpes y ranqueles.

Pueblo Alberdi fue el nombre que sucedió a La Toma una vez ingresada como barrio a la ciudad de Córdoba, tras la sanción de una ordenanza municipal que en 1910 hizo homenaje a Juan Bautista Alberdi con motivo del centenario de la independencia nacional. Se trató de la creación de uno de los principales "Barrio-Pueblo" de Córdoba y cuya extensión era mayor que el actual barrio Alberdi, localizado en el anillo periférico oeste del centro de la ciudad de Córdoba. En la actualidad los adscriptos señalan que dicho nombre fue parte de una serie de prácticas y políticas de invisibilización del gobierno municipal y provincial hacia la comunidad indígena, siendo esta práctica parte culminante del proceso de expropiación y desalojo llevado a cabo a partir de la década de 1860.
} 
Siguiendo a James Brow (1990) podemos entender la aparición y organización de estos grupos bajo el concepto de procesos de comunalización, es decir, como un conjunto de acciones que construyen los sentimientos de pertenencia vinculados a un "estar juntos". Desde la perspectiva del autor la comunalización es construida tanto por la dimensión de la primordialización (creencia compartida de un origen común inmemorial) como por prácticas de reinvención de la tradición, es decir por una serie de acciones que buscan reconstruir ese pasado común para dar sentido a la comunidad en el presente. En nuestro caso, se trata de la formación de comunidades aborígenes comechingonas que rescatan una historia y una identidad como comechingones y que encaran un proceso de reorganización territorial y política ${ }^{4}$.

Ahora bien, en la medida que estos procesos se solapan con imaginarios de la identidad nacional que han sostenido la extinción de las comunidades y al mismo tiempo europeizado a la población local, han sido afectadas por disputas de autenticidad indígena (Palladino, 2014a). En este sentido, estos procesos han lidiado con las memorias hegemónicas y las narrativas oficiales (Ramos, 2011, 2005) que han naturalizado el imaginario de extinción de las comunidades indígenas. Pues aparecieron desde el sector no aborigen de la provincia (vecinos, historiadores locales e incluso algunos funcionarios políticos) relatos que deslegitimaban la pertenencia indígena de los adscriptos comunalizados. Estos relatos ponían en sospecha la autenticidad indígena, por un lado, por dudar de la existencia comechingones en la actualidad y en una ciudad, por otro lado, por sostener que el Pueblo de La Toma no estuvo habitado por comechingones ${ }^{5}$.

En el marco de estos conflictos por la pertenencia y autenticidad étnica, es que los comechingones orientaron sus principales acciones como comunidad. Ellas buscaron fortalecer el relato de continuidad territorial con el pasado, a los fines de tener credibilidad sobre su condición de legítimos indígenas comechingones. De esta manera, por un lado, nos encontramos con relatos que sostienen la desaparición de pueblos indígenas, por el otro, una incipiente movilización y construcción de sentidos del ser comunidad indígena que puso cuestión dichos relatos enfatizando la continuidad de sus pertenencias étnicas con el pasado territorial ancestral. Cabe preguntarse entonces, ¿qué sentidos son movilizados en estas prácticas de comunalización?, ¿estos sentidos entran en disputa con los imaginarios hegemónicos sobre la identidad indígena?

\footnotetext{
El concepto de procesos de comunalización es entendible en el marco de la lectura que Brow hace del texto comunidades imaginadas de Benedict Anderson (1993) en el sentido que son construcciones culturales y sociales, especialmente destacando el papel de las prácticas simbólicas y materiales que participan en dicha construcción. Sólo que Anderson utilizó el concepto para dar cuenta de la formación de los Estado Nación europeos y Brow con esta categoría nos permite entender los procesos de formación de diversas comunidades subalternas. Bustos Argañaraz, un reconocido escritor local, quien fue presidente de la Junta Provincia de Historia Córdoba, se manifestó con dudas sobre la veracidad de la identidad comechingona de los comuneros del Pueblo de La Toma. El autor sostuvo en una nota de opinión de un diario cordobés: "En un artículo aparecido en La Voz del Interior leí que mediante un estudio se ha identificado sangre aborigen en siete familias que habitan desde hace muchos años en barrio Alberdi de nuestra ciudad. Alli se afirma que el descubrimiento acredita su ascendencia comechingona, lo que me lleva a preguntarme sobre la base de qué patrones genéticos se llega a esa conclusión. (...) estimo que se trata de un error. (...) No hay ninguna constancia documental de que en lo que hoy es el barrio de Alberdi hubiera un pueblo de indios a la fecha de la fundación de Córdoba." (Bustos Argañaraz,2008)
} 


\section{El pasado territorial en la construcción de la aboriginalidad y comunalización}

Debido al contexto conflictivo en que participaron las argumentaciones de autenticidad, aquí sostenemos que el pasado territorial jugó un papel fundamental en la construcción de sentimientos de pertenencia en el proceso de comunalización de la Comunidad Comechingón del Pueblo de La Toma. Seguimos a Hall (1996) para dar cuenta que el "afuera constituyente" es parte fundamental de todo proceso de identificación; de modo que las identidades son relacionales, contingentes y constituidas a través de estas relaciones de fuerza. De hecho, al considerar el tipo particular de etnicidad que implica la construcción de una identidad indígena, Briones (1998, 2005) sostiene que la aboriginalidad debe ser entendida en el marco de las relaciones de alteridad en el cual participa la producción de "otros internos" de los estados nacionales y provinciales.

En este sentido nos encontramos con relaciones de fuerza que ponen en tensión los aspectos simbólicos a partir del cual se construye legítimamente la identidad indígena. Acá nos referimos a los imaginarios que consideran la población argentina como blanca y europea, y que ha sido utilizada en el proceso de consolidación del Estado Nacional (Briones, 1998, Frigerio, 2008) expresando que los argentinos son "venidos de los barcos". Pero también es preciso mencionar el carácter provincial de estos imaginarios, en una provincia donde se ha resaltado desde el discurso oficial el orgullo hispánico y donde se consideró a los comechingones extintos ${ }^{6}$.

En esta línea cabe entonces preguntarse sobre los relatos que la comunidad establece para fortalecer la membresía hacia el interior como también la legitimidad hacia el exterior. Así, Brow (1990) sostiene que el pasado juega un papel fundamental para dar sentido de continuidad e identidad común al grupo en el presente. Al mismo tiempo, considera que el pasado es objeto de disputa y conflicto con otras representaciones. En esta línea, otro aspecto que destaca es la vinculación entre la construcción del pasado y las disputas de sentido instalados como doxa.? De la misma manera la antropóloga Ana Ramos (2011) considera que las versiones del pasado "son un rasgo prominente en la lucha hegemónica, puesto que las interpretaciones del pasado y los orígenes comunes son terreno de disputas entre los miembros de un grupo y de éstos con la sociedad mayor (Brow, 1990; Beckett, 1996)" (141). En este marco, observamos que la construcción de prácticas de comunalización se dio conjuntamente con las prácticas de reconstrucción del pasado, jugando un papel clave las representaciones de quienes desautorizaban la autenticidad indígena de los adscriptos.

\footnotetext{
Estos imaginarios operan en el marco de construcciones históricas de alteridad (Briones, 1998) que entrecruzan, en primer lugar, las prácticas de conquista y colonización, en segundo lugar, a la construcción simbólica del estado argentino con sus respectivas políticas de blanqueamiento, europeización (Briones, 1998; Frigerio, 2008) y simultánea invisibilización de grupos indígenas; en tercer lugar, atendiendo a la dimensión provincial de estos imaginarios, por el efecto de las narrativas "cordobesistas" (Bompadre, 2016) que destacaron el carácter hispánico y colonial de la población local.

Basándose en las ideas de Pierre Bourdieu (1977), Brow define a la doxa como un conjunto de creencias y prácticas sociales que son consideradas como "normales" (o como verdad) en determinado contexto social, que se estructura desde la clase dominante para definir el mundo social. Desde esta perspectiva, la doxa tiene un amplio poder simbólico, es la condición para que se mantenga el estado de las cosas en una sociedad (Bourdieu, 1977).
} 


\title{
La construcción del pasado territorial
}

\author{
Narrativas histórico territoriales
}

Cuando la comunidad se visibilizó en 2008 (y en el momento que agentes del gobierno preparaban las fiestas del bicentenario de la patria para el 2010) los comuneros redactaron un folleto de difusión para visibilizarse en el espacio público. En el mismo y en uno de los primeros párrafos, destacan los actores y agencias, procesos, acciones (u omisiones) que contribuyeron a la invisibilización de la comunidad comechingón en el pasado. Especialmente este relato tiende a mostrar la complicidad del Estado Nación argentino en la expropiación de la comunidad y posterior invisibilización.

En la colonia española, instituciones como el Estado, la Iglesia, el Mercado, la Justicia y la Universidad ejercieron un rol socializador con la clara intención de homogeneizar para hegemonizar. Construyeron desde la hegemonía un sistema que no contaba con nosotros y con nuestra cultura. (...) Luego vino el gobierno de la Emancipación nacional. Y nuestra dependencia pasó del gobierno español al gobierno criollo. Mientras muchos en la sociedad argentina se aprontan a celebrar el bicentenario, nosotros queremos recordarle al país, que mientras se desarrollaba el proceso de independencia política, los funcionarios y la burguesía local, comenzaron la compra venta ilegítima de nuestras tierras. (...) (Folleto de promoción de la Comunidad Comechingona del Pueblo de La Toma, octubre 2008: 2. Las cursivas son nuestras).

Ahora bien, mientras observamos un conjunto de enunciados gráficos y orales en los primeros años de comunalización que denuncian la complicidad de estos agentes y agencias en la invisibilización comechingona, también observamos que los relatos de adscriptos construyen una historia en la que considera que los antepasados comechingones existieron y desarrollaron su vida cotidiana, sus vínculos de pertenencia, su organización comunal y territorial previa y durante la reducción del Pueblo de La Toma. En este sentido, la enunciación reiterada expresaba "queremos que Córdoba sepa que nunca nos fuimos... que siempre estuvimos acá" o "Hemos podido salir... nuestra identidad estaba escondida".

Así, en presentaciones públicas los comuneros llevaron a cabo un relato donde argumentaban que eran descendientes de comechingones que vivieron en el Pueblo de La Toma y donde se narraban sus trayectorias familiares. Al presentarse, cada uno comenzaba marcando su ascendencia, mencionando el parentesco con algún "curaca"8 del siglo XIX. En ocasiones reiteradas, cada adscripto mencionaba los términos "silencio", "ocultamiento", "invisibilización" para referirse a que sus familias habían vivido en la clandestinidad hasta el momento de su rearticulación. En este sentido, se presentaba la identificación genealógica con "curacas" y "comuneros" que habitaron el Pueblo y la alusión a la perdurabilidad o continuidad de esas familias en el "territorio de La Toma" hasta la actualidad.

El curacazgo es el sistema de representación política que reivindican los adscriptos, cada curaca es el representante de una o varias familias. 
Entendemos esta operatoria en el sentido que menciona Ramos (2011) cuando utiliza el término "narrativas" para dar cuenta de diferentes matrices de interpretación y selección de hechos del pasado que construyen la historia comunal. En este caso se trata de una narrativa histórica territorial que instituye un relato cronológico y lineal $^{9}$ del presente, estableciendo una continuidad con las prácticas del pasado, aludiendo especialmente a diferentes períodos, eventos y hechos en los que indígenas, curacas y comuneros ejercían territorialidad en el Pueblo de La Toma.

Nos interesa destacar la manera en que dicha narrativa articula los hechos y la comunidad en marcos temporales y espaciales (Halbwachs, 2004). Mientras que los marcos temporales encuadran hechos, acontecimientos y eventos que actúan como marcas disponibles de significación para evocar los recuerdos; los marcos espaciales indican la manera en que los comuneros "graban su forma en el suelo mismo y estructuran sus remembranzas a partir de esta" (Ramos, 2011: 133). Así, la imagen territorial permite otorgar la representación de su estabilidad y de su permanencia en el tiempo.

En nuestro caso, también observamos que esta vinculación cruza entonces los aspectos históricos y geográficos. Por un lado, los sentidos históricos operan aludiendo a una temporalidad que constituye períodos, entre los cuales, adscriptos mencionan: el "territorio ancestral", con la presencia de comarcas indígenas previas a la llegada del español (hasta 1573); la etapa del "pueblo" reducido después de la fundación de la ciudad de Córdoba y la colonización española (1573 a 1810); desde la construcción y consolidación del Estado-Nación argentino a la desarticulación oficial de la comunidad (1810-1880 a 1910), momento de la resistencia a la expropiación y el desalojo. Por último, la comunidad rescata aquellos momentos en que las familias fueron ocultadas e invisibilizadas (1910 a 2007-2008).

Por otro lado, los sentidos geográficos se constituyen en la alusión a los modos de territorialización (Pacheco de Oliveira, 2010) que desde la concepción de un territorio comunitario extenso fue paulatinamente reduciéndose y desarticulándose. Así los comuneros utilizan los términos "reducción", "dispersión", "expropiación”, "desalojo", "invisibilización" y "ocultamiento". En ambos casos, ese pasado territorial es evocado como fractura para construir las continuidades genealógicas de las familias pasadas con las presentes.

Estos modos de construir pasado que están presentes en las narrativas, articulan temporalidades cortas y largas. Esto es factible a partir del cruce de memorias orales con fuentes de archivos documentales y catastrales. Mientras las fuentes orales articulan episodios del siglo XIX y XX recurriendo a la transmisión oral de padres o abuelos de los comuneros; las fuentes de archivo permiten rescatar acontecimientos desde los tiempos inmemoriales. En este sentido, como veremos,

\footnotetext{
Si bien entendemos que pueden existir diferentes y variadas formas de memorialización y construcción histórica, tal como muestran Boullosa y Rodríguez (2014) aludiendo a "la conformación de varias narrativas, de distintas historias, en las cuales ni la linealidad, ni la veracidad ni menos la unicidad son principios organizadores" (16). En este caso del Pueblo de La Toma aparece la versión cronológica y lineal como modo de enunciación del pasado. Esta versión, como veremos, se construye en la articulación con fuentes históricas. Tal como sostienen las autoras, en todo caso la selección de hechos del pasado consta de "materiales optativos, a disposición de las comunidades que pueden, estratégicamente y de acuerdo a los procesos de unidad o diferenciación -al menos- poner de relieve determinados énfasis, acentuar posicionamientos, o reordenar por completo esas narrativas. 'El tiempo es, en definitiva, un material usado para significar'” (Martínez 2010: 68 en Boullosa \& Rodríguez, 2004: 16. Destacados de las autoras).
} 
las fuentes históricas, entendidas como herramientas de las clases hegemónicas que historiaron en clave "invisibilizadora" son utilizadas, manipuladas, leídas a contrapelo.

\section{El uso de mapas catastrales históricos}

Un aspecto destacado en conversaciones, entrevistas y presentaciones de los adscriptos era su identificación con curacas del Pueblo de La Toma, y la asociación de su pertenencia por haber nacido en el territorio ancestral. En reiteradas ocasiones han expresado: "Nosotros somos comechingones del Pueblo de La Toma porque nacimos acá". Al decir "nosotros somos comechingones" (en términos de pertenencia étnica) aparece, seguidamente, la aclaración, "del Pueblo de La Toma" (aspecto territorial), y a veces el argumento: "porque nacimos acá" y/o "porque siempre vivimos acá" (continuidad genealógica). El "acá" hace referencia a una localización física que se delimita dentro de los márgenes del antiguo Pueblo de La Toma, cuyos límites son indicados superando la delimitación municipal de Pueblo Alberdi. Asimismo, el "acá" refiere a este espacio habitado que también se concibe previo a la fundación de la ciudad de Córdoba; si bien como sostuvo un adscripto "acá había chiliznas, cantacaras, suquías que después los redujeron al Pueblito". En este sentido, en el "acá" operan tanto las memorias territoriales vinculadas a la reducción (el Pueblo de La Toma) como la preexistencia territorial a la ciudad; ambas configuran encuadres o marcas espaciales que fijan los sentidos comunales en el pasado y le dan sentido al presente. Así, la referencia al habitar, justificada a través del "nacimos" y/o "vivimos acá", como se manifiesta en el lema "espacio de continuidad originaria" presente en carteles, estandartes y folletos de promoción de la comunidad, diferencia la identidad comechingona de otras identidades.

En este contexto, la utilización de la cartografía catastral histórica ha sido fundamental para el proceso de identificación indígena y construcción del pasado. Por medio de ella, los comuneros buscaron constatar la antigüedad de las familias en el territorio y la posesión de tierras. Pretendieron así otorgar legitimidad a la existencia de la comunidad de La Toma en el pasado, ya que a través de ella se muestran los sectores pertenecientes a la "comunidad de La Toma".

Para ello los comuneros apelaron a un acervo documental conformado por títulos de tierras de parientes, informes de diarios y planos de catastro. Entre los más utilizados encontramos: el plano de 1832, el "Plano de los terrenos de 'La comunidad de La Toma"" de 1882, la "División de terrenos del Pueblito" de 1888, y el plano oficial "Córdoba y las villas que le rodea", entre otros ${ }^{10}$. El primer mapa ha permitido identificar algunos sectores que, desde la perspectiva de los comuneros, pueden haber sido entendidos como los límites jurisdiccionales del antiguo Pueblo de La Toma; así también como la localización de algunas familias dueñas de las tierras y la cantidad de hectáreas que poseían. El segundo, que se titula "División de terrenos del Pueblito" marca la reducción de la cuadrícula urbana y algunos lotes titulados con los apellidos de comuneros. El tercero, ya muestra la división del Pueblo de La Toma sobre la base de la cuadrícula de lotes y manzanas en una villa titulada como "La Toma". Su importancia radica en que permite constatar la expropiación y el loteamiento de las tierras comunales del siglo XIX.

Cabe aclarar que la mayoría de los mapas y planos pertenecen al período comprendido entre 1810 y 1890 . Sólo se reconoce un mapa del período colonial en el cual figura "El Pueblo de La Toma" como una serie de "ranchos" dispersos (Tell, 2010; Page, 2007). 
Es interesante destacar el uso del mapa catastral del año 1890 firmado por Ángel Machado (Figura 1). Según Boixadós (2006), los mapas realizados en Córdoba en la década de 1890 fueron confeccionados a partir de la intencionalidad política de los estados municipal y provincial y de la burguesía local, quienes -bajo el discurso de "modernidad" y bajo efecto del crecimiento urbano de la ciudad hacia el oeste- buscaron apropiarse de las tierras allí ubicadas. En este sentido, la autora sostiene que la cartografía refleja el proceso de fiscalización de tierras y mensuramiento del cual habrían sido víctimas los habitantes del Pueblo de La Toman". De hecho, la expropiación y el desalojo a los que los comuneros se refieren en la actualidad, habrían tenido lugar durante aquellos años ${ }^{12}$.

La interpretación de Boixadós nos permite reflexionar acerca del papel de la cartografía en la construcción del poder nucleado en el Estado y la burguesía local, como documento por medio del cual se evidencia el poder hegemónico (Harley, 2005) ${ }^{13}$. Ahora bien, en tanto fuente, nos ofrece elementos para comprender su papel como instrumento que otorga legitimidad a los reclamos en el proceso de comunalización. En este sentido, la cartografía que en el siglo XIX habría sido útil al accionar del aparato estatal (ya sea para defender los intereses de la burguesía local -en tanto demostraba la mensura de tierras que luego serían apropiadas por funcionarios políticos y propietarios privados- como para reflejar el crecimiento urbanístico de la Ciudad de Córdoba -reflejo que habría contribuido a la invisibilización de los comechingones-) es ahora usado en sentido inverso: como una herramienta de legitimación en la reivindicación comechingona en el proceso de comunalización contemporáneo ${ }^{14}$. El mapa sirve aquí a los fines de constatar la presencia y posesión de tierras de las familias comechingonas en el Pueblo de la Toma. A su vez, permite verificar que en el siglo XIX el Estado efectivamente reconocía la existencia del Pueblo de La Toma en dicho territorio: primero como "comunidad" (en el plano de 1882 "Plano de los terrenos de la

\footnotetext{
Boixadós (2006) muestra la vinculación del Estado municipal y provincial con las clases dominantes con el objeto de ejercer el control sobre el mercado de las tierras. "El despliegue y crecimiento de Córdoba, como yo lo interpreto, especialmente el de mediados del 80 , fue producto de una combinación de improvisación y especulación sujetos a los intereses particulares de un sector que se convirtió en inmobiliarista por el atractivo rédito que produjo el negocio de la tierra. Por encima y relacionado con esto, la presencia de un Estado que poco tuvo de prescindente, al actuar en conjunción con estos particulares, siendo gran parte de ellos miembros activos de la función pública y del negocio de la tierra" (Boixadós, 2006: 3). Estos intereses habrían derivado en la demanda de un mapa que diera cuenta del proceso de mensuramiento de las nuevas tierras apropiadas. Así, la autora explica: "la explosiva extensión y crecimiento de la ciudad de fines de la década de 1880, que desencadenó el origen de once nuevas zonas loteadas en solo tres años, fue producto de un redituable y atractivo negocio de la tierra, más que del resultado de una política urbanística o bien de una intervención de parte del Estado por regular y planificar el espacio" (2). A partir de esto, "la cartografía adquirió un valor fundamental para conocer, reconocer, intervenir, planificar y controlar el espacio constituyéndose en un instrumento de registro y control, pero simultáneamente en una forma de representación de la ciudad, de la ciudad ideal o la que debe ser incorporada en el imaginario ciudadano" (1).

12 Según Boixadós, en el plano de 1889 firmado por Santiago Albarracín -el cual integraba la publicación oficial titulada Bosquejo Histórico, Político y Económico de la Provincia de Córdoba- se incluyen los nuevos barrios con sus respectivos conjuntos de manzanas. Dentro de éstos aparece el Pueblo de La Toma, designado como "el Pueblito". Del mismo modo, el plano de Machado de 1890 expresa esta división y muestra al Pueblo de La Toma solo con el nombre de "La Toma".

13 Harley, inspirado en Michel Foucault, entiende al mapa como un texto y como una forma de conocimiento a través del cual se ejerce poder. Para comprender cómo el poder se ejerce sobre y con la cartografía, distingue dos formas de ejercicio: un poder externo y un poder interno. En el primer caso, los mapas se entraman en el ejercicio de fuerzas en términos materiales (jurídico-burocráticos), en el segundo, los mapas producirían efectos de poder. Dentro de esta contextualización demuestra, por ejemplo, cómo en la sociedad occidental moderna el mapa se ha vuelto crucial para la conservación del poder de las instituciones estatales (entre otras) en tanto herramienta para expandir y conservar sus "fronteras, comercio, administración interna, control de la población y fuerza militar (Harley, 2005: 203). En este marco, podemos comprender el poder ejercido por el mapa de catastro en el proceso de apropiación de los territorios indígenas, en el marco de las instituciones gubernamentales aparecidas tras la constitución del Estado Nación, como por ejemplo el Departamento Topográfico (Maizón, 2013).

14 "Los mapas son imágenes acreditadas. Pueden reforzar y legitimar el statu quo, seamos o no conscientes de ello. Algunas veces son agentes de cambio y pueden, de igual manera, convertirse en documentos conservadores. Sin embargo, en cualquier caso, un mapa nunca es neutral. Cuando parece serlo, la oblicua 'retórica de la neutralidad' parece tratar de convencernos." (Harley, 2005: 206-207).
} 
comunidad 'El Pueblo de La Toma'") y luego como "La Toma" (en el plano de 1890). Asimismo, se constataba que ésta fue dividida (1888 "División de terrenos del Pueblito").

Entonces, en el proceso de comunalización existen dos momentos en los que los mapas de 1832, 1882, 1888 y 1890 (y otra serie de planos e imágenes) adquieren relevancia. El primero tiene que ver con la construcción de argumentaciones que permitan verificar, constatar, probar la existencia de un espacio de pertenencia familiar y comunal en el pasado, de modo tal que se pueda establecer una continuidad entre el lugar de origen y la morada actual; pero también destacar que hubo desalojo y expropiación. Que esta última corresponde a un proceso de urbanización y privatización del territorio, de "tierras comunales". En efecto, el mapa es visto como instrumento que permite denunciar el desalojo por parte de los Estados provincial y municipal y apoyar los reclamos que se fundamentan en la construcción de su propia historia. Así, por medio del plano de 1832 se constata la existencia de "tierras aborígenes" y mediante el de 1890 el hecho de que estas tierras ya se habían tornado fiscales en tanto figuran como manzanas partidas en lotes de particulares. En este sentido el análisis comparativo de ambos mapas permite inferir los cambios en la propiedad de la tierra y su titularidad, en el crecimiento de la ciudad de Córdoba y en sus consecuencias para la comunidad indígena ${ }^{15}$.

El segundo momento se vincula a su utilidad para representar al Pueblo de La Toma en la actualidad, en el contexto de barrio Alberdi y de la ciudad de Córdoba, en el marco del proceso de solicitud de la personería jurídica. Para dicho trámite el INAI solicita la descripción de la ubicación geográfica de la comunidad y "el territorio que la comunidad reconoce como propio". En este punto, los adscriptos identificaron la ubicación de las casas de cada familia en la actualidad y pretendieron contraponerlas con las del siglo XIX, procurando demostrar que varias de las familias que todavía siguen viviendo en el Pueblo de la Toma poseían tierras en el pasado. Incluso quienes ya no vivían en el barrio, reconocieron en estos mapas los lotes pertenecientes a sus antepasados.

Por otro lado, en dicha solicitud los adscriptos realizaron un mapa del Pueblo de La Toma en el que yuxtapusieron el mapa actual de la ciudad de Córdoba con los antiguos límites del Pueblo de La Toma que figuran en el mapa de 1832. En este nuevo mapa, se ubicaron las familias representadas por los curacas procurando demostrar que ellas viven actualmente en el Pueblo de La Toma. En este sentido, el mapa aparece como un elemento más en la construcción de la legitimidad de la reivindicación de la comunidad en el proceso de solicitud de personería jurídica. Como sostuvo una adscripta: "somos comunidad... porque seguimos viviendo acá"

\footnotetext{
En 2016, al asistir a un evento en el Archivo Histórico Municipal con dos adscriptos y mientras buscábamos planos, la archivera nos recomendó interpretar la primera fotografía aérea de la zona de barrio Alberdi de 1924 y compararlo con el mapa de Catastro Machado de 1890. Se observaba que mientras el plano de 1890 poseía una cuadrícula con el trazado urbano, en la imagen todavía no se había materializado del todo en el mismo; es decir que el mapa ya expresaba las intenciones de mensura aun cuando ni siquiera fueron realizadas tres décadas después. Esta reflexión aparece también en el texto de Page (2007).
} 
Figura No 1:

Plano catastral de Córdoba de Ángel Machado, de 1890. En el margen izquierdo, hacia el oeste, se observa "La Toma".

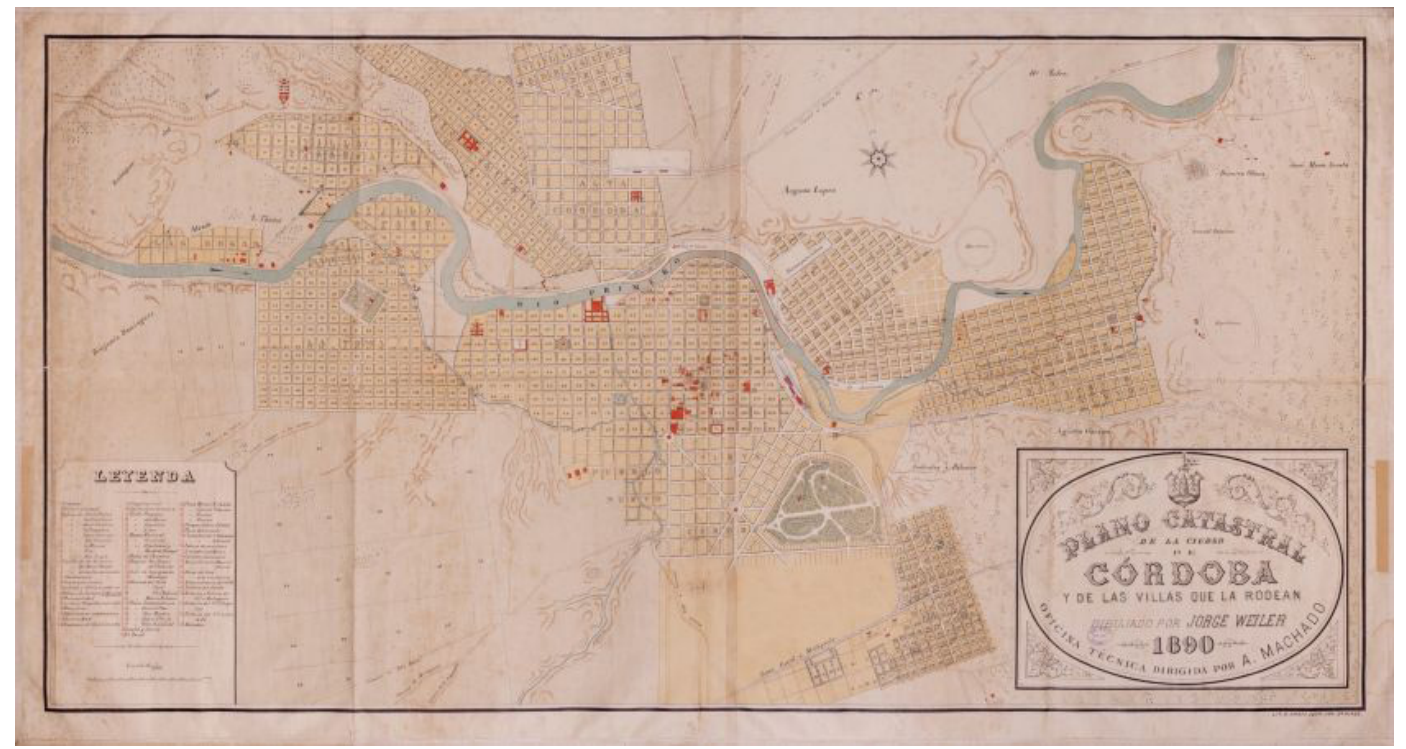

Fuente: Portal web "Córdoba de antaño".

\section{Los documentos históricos en la construcción del pasado territorial}

Así como la cartografía histórica permitió nutrir los relatos sobre el pasado territorial, otras fuentes provenientes de diversos archivos (Archivo Histórico Provincial, en el Archivo del Arzobispado y en el de la Universidad Nacional de Córdoba) aparecen en el mismo proceso: libros, títulos de tierras, diarios de la época y cartas. En este marco, cobraron importancia una serie de artículos publicados en medios de difusión de la ciudad de Córdoba durante el siglo XIX, como el diario católico El Porvenir y el Eco de Córdoba. En estos diarios se menciona la existencia de los comuneros del Pueblo de La Toma, la promulgación de leyes de tierras, remates judiciales y desalojos. En lo que respeta a las cartas, se trata de correspondencias de antiguos comuneros dirigidas al gobierno de la época en contra de la desarticulación de la comunidad.

Así, la documentación permite identificar los intereses de sectores sociales que deseaban apropiarse de las tierras. En este sentido, se le otorga al archivo una función de "prueba" que constata algunos de los argumentos de la historia oral respondiendo y fortaleciéndose frente a la mirada heterónoma.

Ahora bien, ¿qué se reconstruye a través de estas fuentes? Se describen las figuras, los curacas, los episodios, las narraciones sobre los aspectos económicos y territoriales de la comunidad, así como también su relación con el Estado provincial y municipal. Si la cartografía indicaba la "reducción" territorial y la partición y división de tierras, y al mismo tiempo su alusión permitía inferir por oposición un territorio comunitario más amplio, estas fuentes potenciarán dicho pro- 
ceso, contribuyendo tanto a dar a conocer la descripción de la primordialización y naturalización del territorio, como los procesos de expropiación, desalojo e invisibilización a la que fue sometida la comunidad según los adscriptos actuales.

Un elemento que se ha destacado en la construcción del pasado son las "resistencias" llevadas a cabo por los comuneros en el territorio. Aquí se identifican líderes, comuneros y sus acciones vinculadas con la defensa del territorio en el marco de las prácticas de expropiación y el despojo. Así, se han identificado narraciones de la continuidad de lazos con los "ancestros" que se opusieron a su expropiación y habrían sido los personajes claves en dicho proceso ${ }^{16}$.

En esta línea cobra importancia la mención a la figura de don Lino Acevedo, su accionar y la carta que escribió al gobierno municipal en 1882. El papel de Lino Acevedo se centró en construir las argumentaciones y defender políticamente a la comunidad para que se derogasen las leyes de división y mensura (leyes 250 y 854 ) que el gobierno provincial comenzaba a ejecutar desde 1881. Como mostramos recientemente en la alusión a los mapas catastrales, estas leyes se sancionaron para autorizar la división y mensura de las tierras de la Comunidad del Pueblo de La Toma, y permitieron así que las tierras comunales pasaran a manos del estado, para luego ser vendidas a particulares. En la carta Acevedo construye un conjunto de argumentaciones destinadas a promover la derogación de aquellas leyes. Su defensa se apoya en la idea de la importancia del territorio para el desarrollo de la vida de los habitantes del Pueblo de La Toma y de sus relaciones comunales. Así expondrá los motivos por los cuales la comunidad precisa vivir en el territorio, destacando que los ocupantes del Pueblo de La Toma nunca se opusieron al "interés público" y al "avance del progreso", ideas que impulsaba los proyectos políticos de la elite liberal ilustrada de la década de 1880.

"Basta HC con lo expuesto para que se comprenda por lo que pueda consignarlo cuán acreedora es la comunidad del Pueblo de La Toma. Ha sido escuchada en su solicitud, y cuanta justicia se encierra en esta.

Por lo que el HC provincial pido a nombre de la comunidad que represento que tenga a bien suspender la ejecución de la ley del 27 de Dic. del 81 en cuanto ordena la división total de los terrenos del Pueblo de la Toma, sin dejar pastos comunes; pudiendo, sin perjuicio de ello, delinearse la villa y practicar los demás trabajos que se crean necesario y conveniente para la población que se ha ordenado por decreto correspondiente del PE [Poder Ejecutivo]". (Extracto de Carta del Curaca Don Lino Acevedo 1882 ${ }^{17}$ )

\footnotetext{
Estos personajes aparecen como la continuación de un modo de organización y resistencia de "curacas" previos, considerados como "dinastías". En el período al que nos referimos (1880 a 1910), se destacan las menciones a Lino Acevedo, Félix Cortés, Gregorio Cortés, José Álvarez, Domingo Salinas y Pedro Villafañe. Al respecto de esto, nos resulta interesante la idea de "ancestros míticos" de Escolar (2007). La apelación a estos personajes tiene que ver con operaciones de construcción de imaginarios genealógicos, que buscan primordializar las identificaciones y las relaciones comunales para representar una continuidad inmemorial en dicho espacio. Lo relevante es que estos ancestros son remitidos a procesos recientes de construcción del Estado-Nación, aun cuando ellos son entendidos en continuidad con los "caciques de antes" o "naguanes".

17 Para profundizar la lectura sobre el análisis de la carta de don Lino Acevedo en el proceso de comunalización de la Comunidad Comechingón del Pueblo de La Toma, ver Palladino, 2010.
} 
Cabe aclarar que a partir de los años posteriores se ejecutarán dichas leyes, y que finalmente comenzara la expropiación y el despojo a partir de 1885 y 1886, momento que los comuneros consideran "el último grito de libertad" de la comunidad comechingón ${ }^{18}$.Por otro lado, Acevedo continúa demostrando que la comunidad precisa de tierras para continuar con sus actividades económicas que considera fundamentales para la sobrevivencia de la misma.

La carta se presenta como un documento legítimo del Pueblo de La Toma que permite constatar la veracidad de la narrativa que sostiene el dominio, la expropiación y posterior exterminio de la comunidad en el siglo XIX. En segundo lugar, fue usada para explicar algunos aspectos de la vida de la comunidad en el territorio del Pueblo de La Toma en el momento previo al desalojo, así como para construir valoraciones sobre las actividades que llevaban los comuneros en el pasado (por ejemplo, Acevedo en la carta describe el desarrollo de actividades en los pastos comunes, la cría de ganado y la fabricación de ladrillos). En tercer lugar, a través de este documento se identifica un ancestro de la comunidad que se constituye en una figura clave para la construcción del linaje que llega hasta la comunalización contemporánea. Finalmente destacamos que tanto dicha carta como los documentos catastrales anteriormente analizados han permitido reconstruir la delimitación territorial que se hace hoy del Pueblo de La Toma, en tanto la descripción que permite corroborar la localización en el pasado y también el uso del territorio por parte de la comunidad. En este sentido, la carta, al igual que los planos catastrales en diálogo con la historia oral constituyen un corpus documental que da cuenta de personajes, lugares, sitios y referentes espaciales a través de los cuales se construye la historia comechingona.

\section{Mapeando el territorio ancestral}

Otra instancia en donde se evidencia la construcción del pasado territorial tiene que ver con unas jornadas de trabajo en donde se realizó una línea de tiempo que tenía como finalidad dar a conocer el proceso de reducción territorial del Pueblito ${ }^{19}$. Esta línea de tiempo se acompañaba con la construcción de un mapeo colectivo y colaborativo (Ares y Risler, 2013; Ascerald, $2013)^{20}$ que representaba los diferentes períodos en la historia del territorio de La Toma. Los comuneros pretendían representar acontecimientos claves en la historia del despojo, actividades económicas, cosmovisión, usos de la tierra, entre otros. Aquí utilizaron tanto los mapas catastrales como la carta de Don Lino Acevedo (entre otras fuentes como libros y títulos de tierras) para mapear los límites del territorio de La Toma y visibilizar las prácticas de expropiación, reducción y desarticulación de la comunidad en el siglo XIX.

Así, los curacas construyeron cinco períodos para narrar su historia. El primero se denominó "territorio ancestral". Se trata del territorio antes de la fundación de la Ciudad de Córdoba (1573)

\footnotetext{
En este período se desarrollan las leyes que avalan la desarticulación y expropiación de comunidades (años 1882 y 1886) que llevaron a la prohibición del uso de espacios a los comuneros, la subdivisión de los terrenos de la comunidad del Pueblo de La Toma, y desencadenaron en remates y desalojos. En 1885 la ley 1.002 donde las tierras son divididas en razón de "utilidad pública" (CIICA, 2009:48). En 1886 se realiza el desalojo del último comunero, Pedro Villafañe que resiste frente a la policía (por decreto, la policía puede usar la fuerza para desalojar).

19 Se trató de talleres que se llevaron a cabo durante los meses de agosto y setiembre del 2017, en el marco de nuestra investigación doctoral. En esta instancia participaron algunos miembros de la Comunidad Comechingón del Pueblo de La Toma, vecinos, miembros del Instituto de Culturas Aborígenes e integrantes del Centro Vecinal de Barrio Alberdi.

20 Entendemos al mapeo colaborativo como "una instancia a partir de los cuales se pueden favorecer las distintas formas de comprender y señalizar el espacio a través del uso de variados tipos de lenguaje, como símbolos, gráficas e íconos, que estimulan la creación de collages, frases, dibujos y consignas" (Ares y Risler, 2013: 6)
} 
entones habitado por diferentes grupos indígenas (Chiliznas, Cantacaras, Suquías, Siquiman, entre otros). Eran pequeños poblados que ocuparon principalmente las márgenes del Río Suquía, y que según los adscriptos se trataban de comarcas comechingonas previas a la reducción del Pueblo de La Toma. El segundo período (1573-1880) se denominó “Primera reducción del Pueblo de La Toma" y trata del territorio comechingón posterior a la fundación de la Ciudad de Córdoba. Aquí se hace referencia a la llegada de los españoles y la correspondiente esclavización de indígenas y reducción al territorio del oeste. El tercer período (1880 a 1910) lo titularon "Segunda reducción, expropiación y resistencia del Pueblo de La Toma". Aquí se representa la reducción del territorio de La Toma tal como figura en el catastro Machado (con la correspondiente señalización de lotes, manzanas y trazado de calles). Por su parte, se representó en el mapa las acciones de expropiación con símbolos de "prohibición" (de la vida comunitaria, de uso del espacio público, de las actividades económicas). Se enfatiza el período que ellos reconocen como de "ruptura oficial" cuando se ejecuta la Ley de Desarticulación de Comunidades (1885) y el consecuente desalojo, proceso que culmina con la creación de "Pueblo Alberdi" (1910). El período cuatro, comprende desde el año 1910 hasta 2007 y lo titularon "Invisibilización y ocultamiento". Aquí se representan los espacios ocultos de la identidad comechingona (espacios privados donde se transmite la memoria oral) y al mismo tiempo se muestran las prácticas simbólicas del estado que pretendieron invisibilizar a los comechingones (transmisión de identidad nacional en la educación pública). En este sentido, ellos expresan que: "no sólo nos sacaron tierras, sino que nos quisieron borrar del mapa cambiándonos nombres, calles y el mismo barrio. Pero resistimos, nunca huimos, nos quedamos en el espacio privado, manteniendo nuestra identidad en secreto, al interior de nuestras casas". Finalmente, el quinto período es a partir del 2007- 2008 y lo denominaron "Rearticulación de la comunidad y visibilización". Se trata del reencuentro de los comuneros y las actividades y acciones que llevaron a cabo desde entonces.

Figura $N^{\circ} 2$ :

Cartografía colectiva del período uno: "Primera reducción del Pueblo de La Toma"

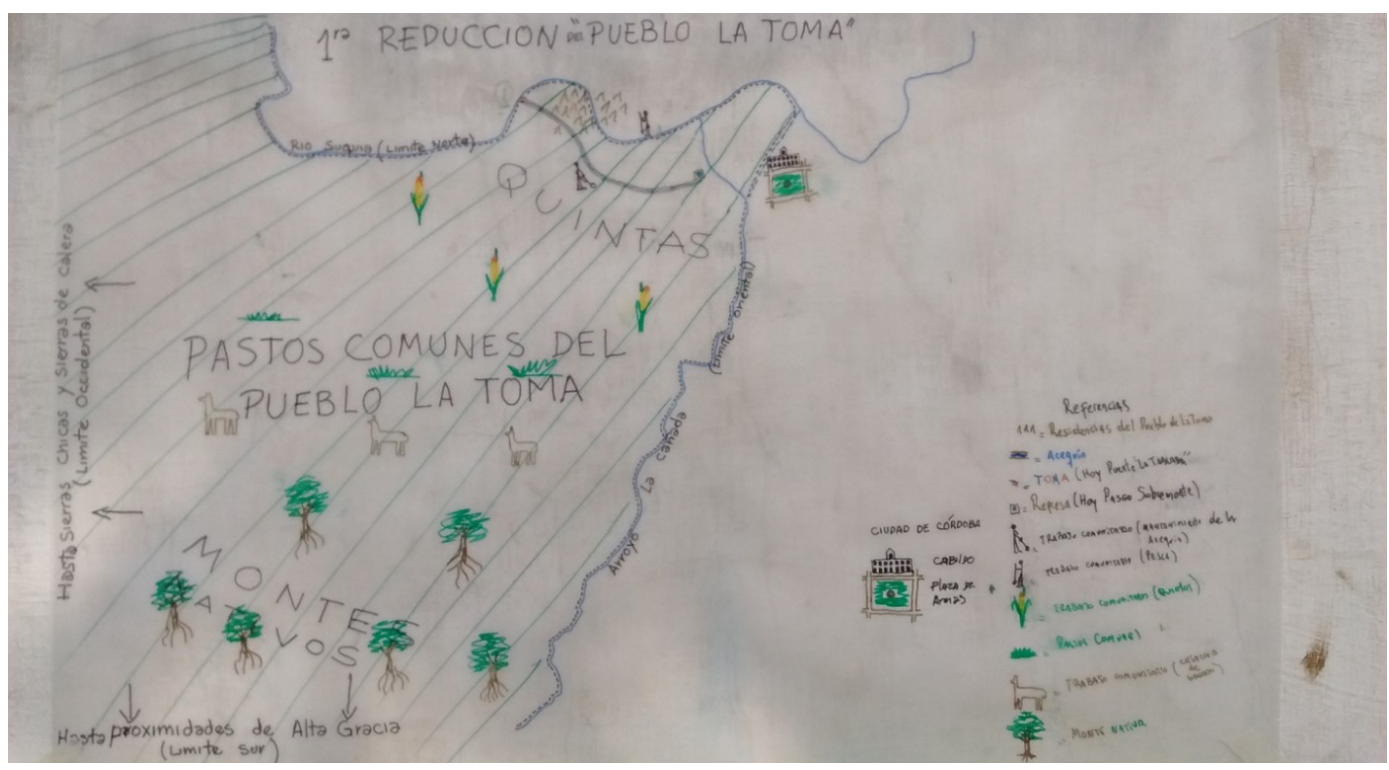

Fuente: Foto del autor - Setiembre de 2017 
Figura No 3:

Cartografía colectiva del período tres: "Expropiación y segunda reducción del Pueblo de La Toma"

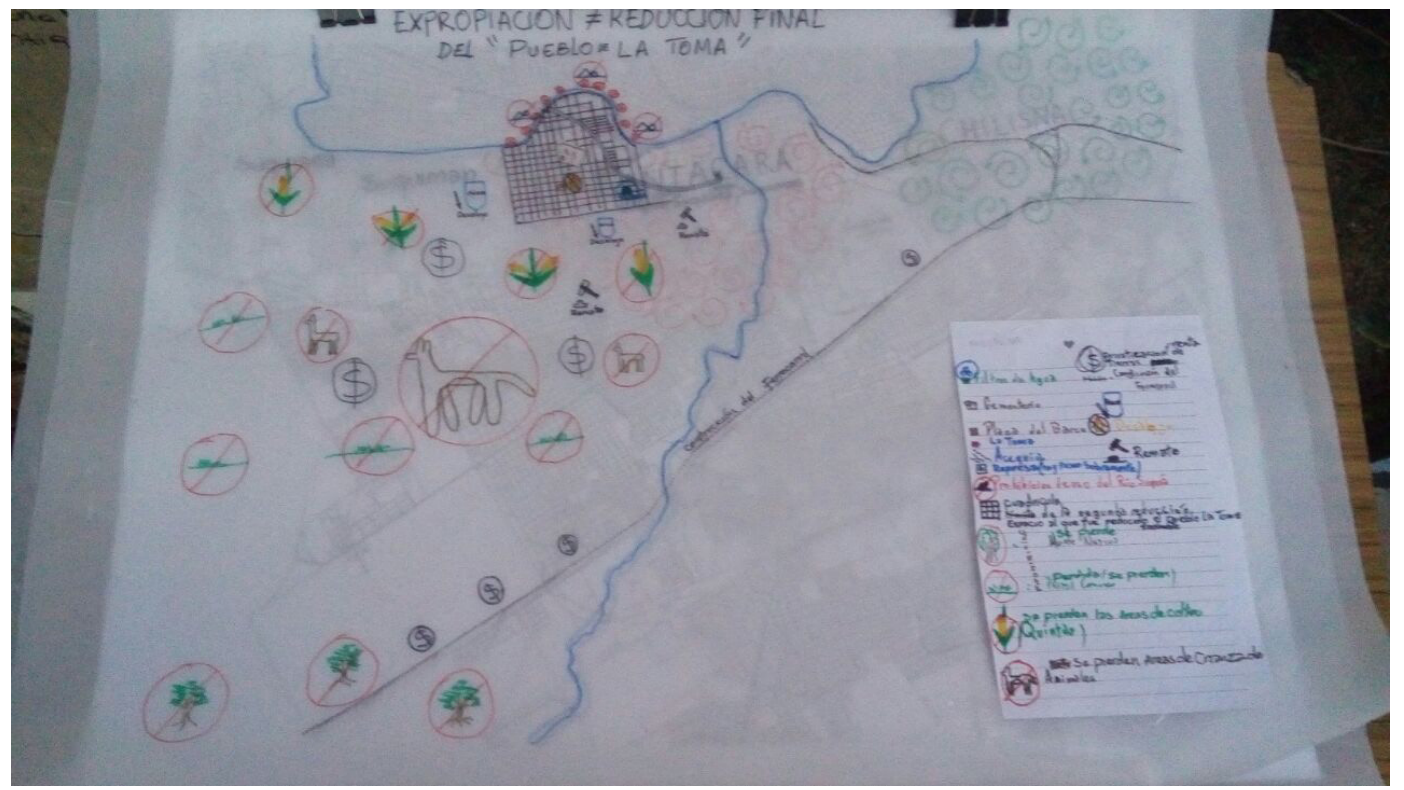

Fuente: Foto del autor - setiembre de 2017.

A modo de ejemplo, observamos dos mapas en proceso ${ }^{21}$ que destacan el territorio del Pueblo de La Toma en el pasado y su paulatina reducción. En el primero (Figura 2), se observa el territorio una vez reconocido por la corona española como Pueblo de La Toma. Acá se han representado los antiguos límites, que comprenden los cursos de agua (Rio Suquía al norte y arroyo La Cañada al este) y que se expande hacia al oeste referenciado como Malagueño y Alta Gracia. En la primera imagen los adscriptos que participaron decidieron mostrar al territorio como un lugar con "monte" caracterizado por el trabajo comunitario, siendo los iconos más representativos aquellos que expresan el trabajo comunitario, las quintas, pastos comunes o el trabajo en la fabricación de tejas. También figura abundancia de monte nativo que después fuera deforestado por el crecimiento de la Ciudad de Córdoba. En el segundo mapa (Figura 3), ya aparecen signos que representan la "prohibición" de las actividades comunitarias en el territorio (de quintas, de ganado, de uso del Río Suquía), al mismo tiempo se dibujaron el avance del estado y del capital, simbolizado por íconos que representan la policía, los remates judiciales y el signo del billete "peso". Por otro lado, también se dibujó la "cuadrícula" que desde la perspectiva de los adscriptos representa el avance de la ciudad sobre su territorio comunitario.

Es interesante destacar la leyenda con la que los adscriptos acompañaron el mapeo y la línea de tiempo, resaltando la importancia del tercer período por ser el momento donde se produce la ruptura oficial de la comunidad:

Las representaciones sobre los mapas que mostramos no son las versiones finales, en tanto se encuentran en proceso de digitalización. Sin embargo, miembros de la comunidad nos han permitido publicarlos. 
En el siglo XIX resistimos a las políticas de tierras y desarticulación de comunidades indígenas; enfrentamos la privatización de nuestro territorio comunal mediante cartas, dialogando y luego resistiendo. Ya habíamos cedido las tierras del cementerio San Jerónimo al "bien público", luego los filtros, pero el gobierno avanzó con calles, manzanas, nos prohibieron el uso del espacio, como nuestro sagrado Río Suquía y finalmente nos desalojaron de nuestras mismas casas. Nuestros curacas Acevedo y Villafañe, en diferentes momentos, resistieron a estas políticas, desde 1880 hasta 1910. El primero representante y síndico, y el segundo siendo sacado por la fuerza de la Policía Provincial. La culminación de este proceso se dio en 1910, cuando por ordenanza municipal, cambian el nombre de La Toma a Alberdi, en homenaje a Juan Bautista Alberdi, por el centenario de la Patria. (Texto redactado por la Comunidad Comechingón de La Toma, Setiembre de 2017).

\section{A modo de cierre}

Hemos observado cómo a través de la construcción de narrativas sobre el pasado territorial los adscriptos fortalecen su identidad comunal en el presente y además disputan sentidos sobre la invisibilización comechingona, de manera que construyen un relato que permite otorgar autenticidad en un contexto considerado de extinción aborigen. Hemos dado cuenta cómo los sentidos implicados en la comunalización se construyen a partir de la reinvención de la tradición y desde la perspectiva de la primordialización de los vínculos. Así, el pasado territorial permite por un lado naturalizar los vínculos en el pasado y visibilizar las rupturas producidas en la comunidad, particularmente a efecto de las políticas del Estado colonial y republicano (en sus diferentes escalas) y sus modos de territorialización (Pacheco de Oliveira, 2010).

Así, a través de las diferentes prácticas de construcción del pasado territorial que observamos, se ponen de manifiesto las oposiciones o contrastes (Cardoso de Oliveira, 2007) de las atribuciones y valoraciones de la comunidad frente a lo "ajeno". Estas oposiciones se asocian a al accionar de diversos agentes gubernamentales y empresarios, asociados con la organización territorial del estado moderno. En el marco de estas oposiciones los adscriptos interpretan dichas prácticas de estos "otros" como propias de la "vida urbana", "moderna" y "capitalista" y contrarias a un "nosotros" inscriptos en un territorio comunal. Es precisamente la alusión a diferentes períodos de tiempo donde se considera que la expropiación, el avance de la urbanización sobre el Pueblo de la Toma y la invisibilización de la comunidad son procesos que participaron en un forzoso intento de desterritorialización. Así, en primer lugar, la expropiación aparece como una desarticulación materializada en procesos judiciales y gubernamentales (leyes o decretos nacionales y provinciales, ordenanzas municipales); en segundo lugar, el despojo o desalojo se presenta como la pérdida del territorio en tanto espacio físico dominado (lotes, moradas, espacios de uso común) por medio de la fuerza física que consuma dicho acto. En tercer lugar, la urbanización del siglo XIX es vista como una estrategia de desarticulación de la vida en comunidad frente al uso territorial capitalista del espacio. Finalmente, la "invisibilización" es considerada como una serie de prácticas tendientes a negar la existencia de comechingones, que se perpetuaron a lo largo del siglo XX por los imaginarios que consideraron su extinción.

En este contexto mostramos el papel que han tenido las fuentes documentales y catastrales en la construcción de relatos sobre el pasado en el proceso de comunalización. Por un lado, los mapas catastrales aparecen como documentos que contribuyen a esta primordialización a partir 
de su utilidad para localizar los lotes de las familias de los antepasados de los comuneros que vivían en el Pueblo de la Toma, cuya extensión y límites también es aludida a través de los documentos cartográficos. Y es sobre la base de este territorio definido, el eje a partir del cual adscriptos actuales establecen una serie de sentidos sobre la comunidad y el territorio en el pasado, como por ejemplo al mostrar la relación armónica y la territorialidad que sus ancestros mantenían con el medio. En este marco, el mapa es presentado como una herramienta legítima que "corrobora" la localización y pertenencia de las familias en el Pueblo de La Toma, en tanto ellas vivían, se relacionaban y poseían lotes o tierras propias en esa área.

Así también, en la medida que estos mapas fueron herramientas del poder estatal (Harley, 2005) nos permiten entender el proceso de apropiación de los territorios indígenas, en el marco de las instituciones gubernamentales aparecidas tras la constitución del Estado Nación. A partir de ellos se permite constatar las estrategias del poder hegemónico por el control territorial del Pueblo de La Toma. Así, y en la medida que dicho poder se desplaza espacialmente sobre lo que los curacas denominan el "territorio comunitario", el mapa da cuenta de los dispositivos técnico-jurídicos que visibilizan un proceso de estriamiento del territorio (Deleuze \& Guattari, 1994) en efecto de la producción capitalista del espacio urbano. Por otro lado, permite también "objetivar" y constatar el relato de la mensura, división y expropiación del que fue objeto el Pueblo de La Toma. Así también la cartografía permite ver que el territorio construido es el "deseado" por los sectores hegemónicos y donde no cabe lugar de existencia a la comunidad indígena.

Por otro lado, la sistematización de documentos históricos en el proceso de comunalización ha contribuido a fortalecer la posición de que existe un pasado que no solo se hace presente en la memoria oral, sino que también se encuentra registrada en fuentes oficiales. En este sentido, la búsqueda de documentación ha sido importante en tanto da cuenta del "poder de la palabra escrita" (Muñoz Morán, 2010: 363) para los adscriptos, especialmente porque se considera que quienes construyeron dichos documentos fueron los protagonistas de la expropiación. Así las fuentes ofrecen insumos para reconstruir los hechos y experiencias que se narran en el relato histórico y geográfico de la comunidad, por cuanto también constituye "evidencia empírica" sobre la existencia de la comunidad en el pasado. Asimismo, fortalece y construye la secuencia de su desaparición (en los tres momentos que citamos: expropiación, desalojo e invisibilización) y el protagonismo del estado en este proceso. Como sostuvo un comunero: "Ahora que estudiamos científicamente nuestro pasado, me doy cuenta de que [las historias orales] son ciertas". O tal como figura en un escrito de divulgación: "Curiosamente esos mismos sectores de poder, movidos por el negocio de las tierras y las aguas, olvidaron quemar los documentos (...) Esos archivos gritan nuestro ayer. Ese ayer fecundo en luchas y resistencias". (Folleto de presentación de la Comunidad Comechingona del Pueblo de La Toma, 2008:1). En este sentido es interesante la expresión de Derrida (1997) cuando sostiene que no hay "ningún poder político sin control del archivo, cuando no de la memoria" (12).

El conflicto que se desencadena en torno a la autenticidad aborigen nos resulta interesante para entender los efectos de poder y la eficacia simbólica de las prácticas estatales que se enraízan en la creación y consolidación del Estado Nación argentino, pero también de las prácticas materiales y simbólicas del estado provincial y municipal de Córdoba. Consideramos que la identificación de tales prácticas, espacial y temporalmente situadas, nos permite entender las 
maneras en que los procesos de comunalización indígena en Córdoba disputan formaciones de alteridad (Briones, 2005) asociados a contextos de larga duración. Los procesos sociales e históricos fueron definiendo criterios, formas de invisibilización de las identidades aborígenes y asentaron un imaginario que situaba a los mismos en una lejanía en términos espaciotemporales. Como sostiene Bazcko (1991), los imaginarios colectivos son piezas de control y de ejercicio de poder. Así, designar una "identidad colectiva es, por consiguiente, marcar su 'territorio' y las fronteras de éste, definir sus relaciones con los "otros", formar imágenes de amigos y enemigos, de rivales y aliados (...)" (28).

Atender a los sentidos disputados por las comunidades aborígenes en sus procesos de comunalización nos permite también dar cuenta que los imaginarios hegemónicos sobre la nación y lo nacional se perpetúan. Así, entender que el estado se reproduce en proceso de narración (Bhabha, 2000) o fabricación performativa, buscando instituirse como una comunidad natural e identidad de origen que trasciende los individuos y las condiciones sociales (Balibar, 1991). De esta manera, analizar los procesos de comunalización indígena, especialmente las prácticas inscriptas por la reconstrucción del pasado en contextos de disputas de autenticidad, nos permite revisar y desnaturalizar estos imaginarios sociales hegemónicos.

\section{Bibliografía}

ACSELRAD, H. Cartografia social, terra e território. Rio de Janeiro: IPPUR/UFRJ, 2013.

ANDERSON, B. Comunidades imaginadas. Reflexiones sobre el origen y la difusión del nacionalismo. México: Fondo de Cultura Económica, 1993.

ARIAS, S. "Mapeo autónomo y defensivo en la Zonal Pewence". En: 4tas Jornadas de Historia de la Patagonia: Universidad Nacional de Comahue, Bariloche. 2010.

ARES, P. \& RISLER, J. Manual de mapeo colectivo: recursos cartográficos críticos para procesos territoriales de creación colaborativa. Buenos Aires: Tinta Limón, 2013.

BACZCKO, B. Los imaginarios sociales. Memorias y esperanzas colectivas. Buenos Aires: Nueva Visión, 1991.

BALIBAR, E. La forma nación: historia e ideología. En: BALIBAR, E. y WALLERSTEIN, I., Raza, Nación y Clase. Madrid: lepala, 1991, p. $135-169$.

BHABHA, H. Narrando la nación. En: BRAVO, A. F. (comp.) La invención de la nación. Lecturas de identidad de Herder a Homi Bhabha. Buenos Aires: Manantial, 2000, p. 211 -223.

BOIXADÓS, C. Las representaciones cartográficas de la Ciudad de Córdoba. Entre 1870 a 1930. En: LOIS, C.(coordinadora) Imágenes y lenguajes cartográficos en las representaciones del espacio y del tiempo. I simposio iberoamericano de historia de la cartografía. Universidad de Buenos Aires, 2006, p. 17 - 27. 
BOMPADRE, J. (Des) Memorias de la Docta. De barbudos miscegenados a comechingones comunalizados: procesos contemporáneos de emergencia étnica en Córdoba. Tesis de doctorado en Ciencias Antropológicas de la Facultad de Filosofía y Humanidades, Universidad Nacional de Córdoba. 2016.

BOULLOSA-JOLY, M. \& RODRÍGUEZ, L. Fuentes etnográficas e históricas: repensando la relación entre pasado y presente. el caso de la comunidad indígena de Amaicha del Valle (Tucumán). Memoria Americana. Cuadernos de Etnohistoria, Argentina, 2014, Vol. 22, No 2, p. 43-66. Disponible en internet: <http://ppct.caicyt.gov.ar/index.php/memoria-americana/article/view/4918>.

BOURDIEU, P. Outline of a theory of practice. Cambridge: Cambridge University Press, 1977.

BRIONES, C. La alteridad del "cuarto mundo". Una deconstrucción antropológica de la diferencia. Buenos Aires: Serie Antropológica Ediciones del Sol, 1998.

Formaciones de alteridad: contextos globales, procesos nacionales y provinciales. En: BRIONES, C. (comp.) Cartografías Argentinas. Políticas indigenistas y formaciones provinciales de alteridad. 1ed. Buenos Aires: Antropofagia, 2005, p. 11-44.

BROW, J. Notes on Community, Hegemony, and Uses of the Past. Anthropological Quarterly, 1990, No 63, V.1, p. 1-6.

CARDOSO DE OLIVEIRA, R. Identidad étnica, identificación y manipulación. En: CARDOSO DE OLIVEIRA, R. Etnicidad y estructura social. México: Ciesas, 2007, p. 47-86.

CIICA. Los hijos del Suquía. Los Comechingones del Pueblo de la Toma, actual barrio Alberdi, ayer y hoy. Córdoba: Imprentica, 2009.

DELEUZE, G. \& GUATTARI, F. Mil mesetas. Capitalismo y esquizofrenia. Valencia: Pre-textos, 1988.

DEL RIO, M. Memorias de expropiación. Sometimiento e incorporación indígena en la Patagonia 1872-1943. Buenos Aires: Universidad Nacional de Quilmes, 2005.

DERRIDA, J. Mal de archivo. Una impresión freudiana. Madrid: Trotta, 1997.

ESCOLAR, D. Los dones étnicos de la Nación: identidades huarpe y modos de producción de soberanía en Argentina. Buenos Aires: Prometeo, 2007.

FRIGERIO, A. De la "desaparición" de los negros a la "reaparición" de los afrodescendientes: Comprendiendo la política de las identidades negras, las clasificaciones raciales y de su estudio en la Argentina. En: LECHINI, G. (comp.) Los estudios afroamericanos y africanos en América Latina: herencia, presencia y visiones del otro. Buenos Aires: CLACSO, 2008, p. 117-144.

GORDILLO, G. \& HIRSCH, S. Movilizaciones indígenas e identidades en disputa en Argentina. Buenos Aires: Prometeo, 2010. 
HAESBAERT, R. O mito da Desterritorialização. Do "fim dos territórios" à multiterritorialidade. Río de Janeiro: Bertrand, 2004.

HALL, S. Introducción: ¿Quién necesita la 'identidad'? En: HALL, S., DU GAY, P. (editores). Cuestiones de Identidad. Buenos Aires: Amorrortu, 2003, p. 13-39.

HALBWACHS, M. La Memoria Colectiva. Zaragoza: Prensa Universitaria de Zaragoza, 2004.

HARLEY, B. La nueva naturaleza de los mapas. Ensayos sobre la historia de la cartografía. México: Fondo de Cultura Económica, 2005.

LÁZZARI, A. Deseo de autenticidad, sospecha y autonomía: la revitalización de la lengua en el reconocimiento del pueblo indígena Rankülche. En: GORDILLO, G. y HIRSCH, S. (editores). Movilizaciones indígenas e identidades en disputa en Argentina. Buenos Aires: Prometeo, 2007, p. 147-172.

MAIZÓN, A. S. Construyendo el territorio: contexto institucional, prácticas y dinámicas de la Agrimensura en la provincia de Córdoba, Argentina. Fines del siglo XIX. Revista Brasileira de História da Ciência, Rio de Janeiro, 2013, Vol. 6, No 1, p. 89-105. Disponible en internet: https://www.sbhc. org.br/arquivo/download?ID_ARQUIVO=999.

MUÑOZ MORÁN, O. Lo que nos dice la forma. Etnografía de los archivos locales indígenas. Revista Colombiana de Antropología, 2010, Vol. 46, № 2, p. 353-377. Disponible en internet: http://www. scielo.org.co/pdf/rcan/v46n2/v46n2a06.pdf

OLIVEIRA, P. ¿Una etnología de los indios misturados? Identidades étnicas y territorialización en el Nordeste de Brasil. Revista Desacatos, 2010, N O 33, p. 13-32. Disponible en internet. https:// desacatos.ciesas.edu.mx/index.php/Desacatos/article/view/352.

PAGE, C. El pueblo de indios de La Toma en las inmediaciones de Córdoba del Tucumán. Un ejemplo de asentamiento periférico. Siglos XVII al XIX, Cuadernos de Historia, Serie Economía y Sociedad, 2007, No. 9, p. 105-137. Disponible en internet: https://revistas.unc.edu.ar/index.php/ cuadernosdehistoriaeys/article/view/9941.

PALLADINO, L. Procesos de Comunalización y Territorio. El Caso de la Comunidad Comechingona del Pueblo de La Toma (2008-2009), Córdoba. Tesis de grado de la Licenciatura de Geografía, Facultad de Filosofía y Humanidades, Universidad Nacional de Córdoba, 2010.

Usos del pasado territorial en el proceso de comunalización de los Comechingones del Pueblo de La Toma, Córdoba, Argentina. Corpus [En línea], 2014a, Vol. 3, No 2. Disponible en internet: http://corpusarchivos.revues.org/512.

Esencialismo indígena y autenticidad en disputa. Análisis de la tramitación de la personería jurídica en la reivindicación de la comunidad comechingón del pueblo de la toma (20082009). Intersticios de la cultura y de la política latinoamericana, 2014b, Vol. 3, No 5, p. 69-92. Disponible en internet: https://revistas.unc.edu.ar/index.php/intersticios/article/view/7510. 
RAMOS, A. Narrativas de origen y sentidos de pertenencia. Runa, archivo para las ciencias del hombre, 2005, Vol. 25, N01, p. 123-142. Disponible en internet: http://revistascientificas.filo.uba.ar/ index.php/runa/article/view/1258.

Perspectivas antropológicas sobre la memoria en contextos de diversidad y desigualdad. Alteridades. Universidad Autónoma Metropolitana Unidad Iztapalapa, Distrito Federal: México.2011,Vol. 21, No 42, p. 131-148.

STAGNARO, M. "Casi desde la nada". Narrativas, organización y subjetividades en la reemergencia de originarios urbanos comechingones en la ciudad de Córdoba (Argentina). Tesis de maestría en Antropología, Facultad de Filosofía y Humanidades, Universidad Nacional de Córdoba, 2014.

Representaciones escolares acerca de "lo Comechingón" en Córdoba. Revista del Museo de Antropología, 2011, Vol. 4, No 1, p. 227-234. Disponible en internet: http://publicaciones. ffyh.unc.edu.ar/index.php/antropologia/article/view/371/621.

TELL, S. Expansión urbana sobre tierras indígenas. El pueblo de La Toma en la Real Audiencia de Buenos Aires. Mundo Agrario [On Line]. 2010, N²0. Disponible en: http://www.scielo.org.ar/ scielo.php?pid=\$1515-59942010000100009\&script=sci_arttext.

\section{Fuentes de internet}

BUSTOS ARGAÑARAZ, 2008. http://www.adecirverdad.com/los-indios-del-pueblito-no-eran-comechingones. Recuperado el 13 de julio de 2018.

PLANO CATASTRAL ANGEL MACHADO, 1890. Fuente: http://www.xn--cordobadeantao-2nb. com.ar/institucional/cartografia-de-antano/cartografia-capital/plano-catastral-cordoba-ciudad. 1890\#!Plano_catastral_de_la_ciudad_de_Cordoba_1890. Recuperado el 10 de julio 2017. 